\title{
Capital Social e Políticas Públicas no Brasil: comparando duas cidades na Região Metropolitana de Porto Alegre
}

\author{
Everton Rodrigo Santos' \\ Daniela Muller de Quevedo 2
}

\section{Resumo}

O objetivo deste artigo é analisar as razões que determinam a avaliação satisfatória das políticas públicas, no estado do Rio Grande do Sul em duas cidades da região metropolitana de Porto Alegre, Novo Hamburgo e São Leopoldo. Para tanto, a partir da revisão da bibliografia especializada, construímos um quadro teórico sinérgico que leva em consideração tanto as implicações institucionais formais em si (neoinstitucionalismo), bem como os padrões valorativos locais (a cultura política). Nossa hipótese de trabalho é que o capital social, próprio da cultura política local existente nas cidades em tela, constitui-se num aliado às instituições políticas, pois ele favorece positivamente a avaliação do desempenho das políticas públicas municipais. A metodologia utiliza os resultados de duas pesquisas quantitativas, tipo surveys domiciliares, aplicadas em Novo Hamburgo e em São Leopoldo, com amostras probabilísticas totalizando cerca de 1200 questionários, com erro amostral de $4 \%$ e confiança de $95 \%$, entre os meses de janeiro e abril de 2012 e junho e julho de 2013 pelo Centro de Pesquisa e Planejamento da Universidade Feevale (CPP/Feevale), bem como pesquisa documental aos sites das referidas prefeituras, do IBGE, do Tribunal de Contas do Estado do Rio Grande do Sul (TCE) e da Fundação de Economia e Estatística do Rio Grande do Sul (FEE).

Palavras-chave: Capital social. Instituições. Cultura política.

I Consultor e avaliador da CAPES, professor da Universidade Feevale e da Universidade Luterana do Brasil, atua no ensino da graduação e pós-graduação stricto sensu. Pesquisador vinculado ao Grupo de Pesquisa Capital Social e Desenvolvimento Sustentável na América Latina da Universidade Federal do Rio Grande do Sul (UFRGS) e ao Grupo Metropolização e Desenvolvimento Regional da Feevale. Email: evertons@feevale.br.

2 Professora da Universidade Feevale, atua no ensino da graduação e pós-graduação stricto sensu. Consultora no Centro de Pesquisa e Planejamento CPP da Universidade Feevale. Email: danielamq@feevale.br. 


\section{Introdução}

Um dos efeitos da democratização da sociedade brasileira nas últimas décadas tem sido não somente a rotinização das eleiçôes em seus diferentes níveis, como o surgimento de uma demanda crescente da populaçáo do país sobre os gestores e suas políticas públicas. Este é um fenômeno típico de sociedades ditas "em desenvolvimento".

Destarte, uma das grandes questóes colocadas ao Estado neste início de século é exatamente sobre sua eficiência e capacidade em atender as demandas provenientes da sociedade. Isto tem nos remetido diretamente às relaçóes entre Estado e sociedade, buscando identificar: quais sáo as variáveis que podem determinar uma avaliação satisfatória das políticas públicas municipais? Sob que condiçóes políticas institucionais ou mesmo societais podemos ter um bom desempenho de governos locais?

Buscando responder a estes questionamentos, o objetivo deste artigo é analisar as razóes que determinam a avaliaçáo satisfatória das políticas públicas, especialmente no estado do Rio Grande do Sul em duas cidades da regiáo metropolitana de Porto Alegre, a saber, Novo Hamburgo e Sáo Leopoldo. Estes dois municípios estáo situados hoje no Corede do Vale do Rio dos Sinos (Conselho Regional de Desenvolvimento do Vale do Rio dos Sinos) e sáo conhecidos por serem o "berço da imigraçáo alemâ" no século XIX no estado.

A despeito de serem cidades nascidas sob a mesma matriz de imigração alemá, hoje apresentam certas dessemelhanças em seu "timing" de emancipaçáo política institucional, número de habitantes, dotaçóes orçamentárias. Novo Hamburgo, por exemplo, possui hoje cerca de 240.000 habitantes e Sáo Leopoldo possui cerca de 215.000 habitantes; no entanto, seus IDHs (0,747 em Novo Hamburgo e 0,739 em Sáo Leopoldo) são muito próximos de acordo com o último (PNUD, 2010). Que fatores podem estar determinando o melhor ou o pior desempenho na avaliaçáo de suas políticas públicas? $\mathrm{Ou}$, dito de outra forma, que fatores podem facilitar as açóes governamentais e consequentemente a implantaçáo de políticas públicas em cada cidade analisada? A eficiência, de um governo municipal, depende das instituiçóes políticas ou da cultura política dos seus cidadáos?

As respostas a estas questóes são controversas, e a bibliografia especializada, tais como Robert Putnam (2000, 1996), Douglas North (2001), Hall e 
Taylor (2003) entre outros, tem-se bifurcado basicamente em duas vertentes para dar conta de explicar como um governo pode ter um bom desempenho. Há uma vertente teórica chamada, no sentido lato sensu, neoinstitucionalista, que dá ênfase de uma maneira geral aos aspectos políticos institucionais do Estado. Chama a atençáo para o fato de que um bom desempenho de um governo democrático dependeria da arrumaçáo de suas partes formais, de que instituiçóes podem sim influir sobre a sociedade, através da moldura de comportamentos políticos, estimulando ou inibindo os atores. Demonstraremos este argumento no tópico "Políticas Públicas e a Primazia das Instituiçóes”.

No segundo tópico, "Políticas Públicas e a Primazia da Cultura", inverteremos o argumento, demonstrando que a cultura política é sim um fator determinante do desempenho governamental local. Para esta vertente, um bom governo dependeria dos costumes, dos valores de uma sociedade, de suas práticas políticas que ajudariam as instituiçóes.

No terceiro e último tópico, "Um Sinergismo Possível", demonstraremos que instituiçóes políticas que encontram uma sociedade organizada, horizontalizada e detentora de capital social, portanto fértil socialmente (sinergismo entre as duas variáveis), possuem melhores condiçóes de obter êxito em seus propósitos, conforme os dados empíricos arrolados por nós nesta pesquisa.

Nossa hipótese de trabalho sugere que o capital social, aliado às instituiçóes políticas, incide positivamente sobre o bom desempenho dos governos e consequentemente de suas políticas públicas.

Este artigo justifica-se sob o argumento de que comprovar a hipótese da relaçâo entre capital social e satisfaçáo com as políticas públicas significa demonstrar que o sucesso de reformas políticas, de investimentos públicos, está relacionado náo somente com a qualidade das leis e instituiçóes, dos governos em implementá-las, quanto também da qualidade do tecido social no qual ela é implantada.

A metodologia utiliza os resultados de duas pesquisas quantitativas, tipo surveys domiciliares, com amostras probabilísticas por conglomerado, compostas de 613 questionários aplicados em Novo Hamburgo e 600 em Sáo Leopoldo, com erro amostral de $4 \%$ e confiança de $95 \%$, sendo divididos por bairros e quadras, entre os meses de janeiro de 2012 a junho de 2013, respectivamente, pelo Centro de Pesquisa e Planejamento da Universidade Feevale 
(CPP/Feevale). Com base no mapa da cidade, delimitaram-se os bairros e as quadras, seguido de um sorteio aleatório simples das quadras dentro de cada bairro. No momento da coleta em cada quadra sorteada foi realizada uma amostragem sistemática dos domicílios, obedecendo ao critério do número de domicílios a serem avaliados a cada quadra. A coleta de dados foi realizada pela equipe de entrevistadores do Centro de Pesquisa e Planejamento da Universidade Feevale através de questionário padráo com 40 questóes entre abertas e fechadas, somente nos domicílios do município, com pessoas de 16 anos ou mais de idade (por serem consideradas eleitoras). Os dados coletados foram analisados no programa estatístico SPSS. Para comparar a satisfaçáo dos serviços públicos entre os níveis do Indicador de Capital Social foi utilizado o teste não paramétrico Kruskal-Wallis, e o teste de Mann-Whitney para comparaçáo da satisfaçáo dos serviços públicos entre os níveis agrupados do Indicador de Capital Social. A inferência estatística foi realizada considerando um nível de significância de 5\%.

Também foi utilizada pesquisa documental aos sites das referidas prefeituras, do IBGE, do Tribunal de Contas do Estado do Rio Grande do Sul (TCE) e da Fundaçáo de Economia e Estatística do Rio Grande do Sul (FEE).

\section{Políticas públicas e a primazia das instituições}

Cabe destacar, conforme Souza (2006), que as políticas públicas correspondem a um campo teórico e metodológico que tem na açáo do Estado seu principal escopo de estudo. Na tradiçáo europeia dos estudos sobre políticas públicas, a preocupaçáo residia no Estado e em suas instituiçóes, deixando em segundo plano a avaliaçáo da produçáo dos governos. É somente com a tradição americana, que a área surgiu com a preocupaçáo sobre a açáo dos governos, no âmbito da administraçáo pública, tendo como pressuposto que aquilo que o governo faz ou deixa de fazer é passível de ser analisado cientificamente na academia (PASE; SANTOS, 2011; SOUZA, 2006).

No caso brasileiro, apesar de os estudos de políticas públicas estarem imbricados com a produção bibliográfica da formação do Estado nacional, a análise de políticas públicas vai expandir-se efetivamente a partir da década de 1980, com a transiçáo dos regimes autoritários para democracias, na medida em que este novo cenário abriu a participaçáo da sociedade nos processos 
de formulação e decisão governamental, bem como a produção acadêmica tornou-se mais abundante. Mas o que sáo políticas públicas?

De maneira muito sucinta, podemos dizer, neste artigo, que entendemos como políticas públicas o conjunto de açóes do Estado (no caso em tela das prefeituras analisadas) postas em marcha através de programas e de projetos para efetivar concepçôes a cerca da saúde, da educação, da assistência social, da segurança, da economia, da infraestrutura entre outras (PASE; SANTOS, 2011) 3. Estas "açóes do Estado" podem ser colocadas em prática, grosso modo, "de cima para baixo", através das instituiçóes governamentais, levando-se em conta a primazia das instituiçóes para a elaboração e consecução das políticas públicas, ou vice-versa, como veremos na sequência deste artigo ${ }^{4}$.

A primazia das instituiçóes em determinar o comportamento de atores, dos governos, da economia, ou mesmo do desenvolvimento econômico, caracteriza a vertente teórica do neoinstitucionalismo como corrente de pensamento que tem suas origens no século XX nos Estados Unidos. Contudo, ela náo é uma corrente de pensamento unificada, mas abarca três métodos distintos de análise, segundo Hall e Taylor (2003), o institucionalismo histórico, o institucionalismo da escolha racional e o institucionalismo sociológico. Para estes autores, os institucionalistas históricos entendem que a organizaçáo institucional da comunidade estrutura os comportamentos, estabelece padróes de interaçáo, definindo portanto os resultados finais da ação humana. Para os "históricos", as instituiçóes são as regras, normas e convençóes oficiais. Diferentemente desta perspectiva, os institucionalistas racionais acreditam em atores políticos que se comportam de maneira utilitária, procurando através

3 Uma digressão mais completa sobre análise de políticas públicas pode ser encontrada em outro trabalho desenvolvido por nós em: PASE, H. L.; SANTOS, E. Capital social e políticas públicas na América Latina. In: BAQUERO, M. (Org.). Cultura(s) política(s) e democracia no século XXI na América Latina. Porto Alegre: UFRGS, 201 I. V. I, p. 69-93.

4 Partimos do pressuposto de que as políticas públicas podem ser avaliadas objetivamente através dos investimentos públicos feitos pelos governos como também através da avaliação subjetiva da satisfação da população sobre estas políticas, pois, em última análise, são elas que usufruem ou não destas ações. Aqui, compartilhamos da compreensão de Popkin (1994) da "racionalidade de baixa informação" para quem o cidadão comum pode sim adquirir conhecimento sobre seu entorno, sobre políticas econômicas ou de saúde, mesmo com baixa informação, pois são eles, os cidadãos que vivem o cotidiano das cidades, que compram no mercado, que vão ao médico, que têm filhos na escola e, portanto, podem emitir uma opinião com base na sua experiência. Assim, a satisfação ou não com uma política pública da população não é uma mera opinião, mas sim um indicador do funcionamento desta politica. 
da aplicação da racionalidade e de cálculos estratégicos maximizar seus ganhos pessoais, levando em conta o comportamento dos outros. Aqui as instituiçóes são os acordos solidários entre atores que compartilham vantagens. Temos assim uma aposta dos primeiros na estrutura e destes últimos no indivíduo.

Para os institucionalistas sociológicos, as instituiçóes exercem sua influência náo somente por especificarem o que fazer, mas, sobretudo, o que se pode imaginar fazer num contexto dado; em outras palavras, o conceito de instituiçáo náo se resume às regras e leis, porém ao "sistema de símbolos", aos "modelos morais" incorporados pelos indivíduos (HALL; TAYLOR, 2003). Neste sentido, pensamos que esta concepçáo neoinstitucionalista está na fronteira senão no diálogo com as concepçóes culturalistas, pois ela quebra com a dicotomia instituiçóes e cultura, dando ênfase, desta forma, aos comportamentos apreendidos sob o abrigo das instituiçóes. Portanto, objetivando dialogar com as teorias "neoinstitucionalistas" e "culturalistas", importam-nos sublinhar, "de cima para baixo", como já dissemos, as configuraçóes estatais, as estruturas que conformam, junto com os aspectos culturais, os comportamentos e as políticas públicas ${ }^{5}$.

Assim sendo, as configuraçóes institucionais que o Estado teve ao longo de sua formaçáo, o desenho dos municípios, acabaram dando um contorno político para o processo de desenvolvimento local inegáveis, como dotaçóes orçamentárias, leis municipais etc.

Como lembra Siedenberg (2003), é a partir de 1804 que os portugueses promoveram a primeira divisão territorial do Rio Grande do Sul (na época Província de São Pedro do Rio Grande do Sul), criando inicialmente $4 \mathrm{mu}$ nicípios, com a finalidade de ocupar estratégica e militarmente a região: Rio Grande, Porto Alegre, Santo Antônio da Patrulha e Rio Pardo. Assim, ao longo de sua história política tivemos outras subdivisóes, criando-se 88 municípios no século XIX; inclusive o próprio município de Sáo Leopoldo, objeto de análise, foi criado em 25 de julho 1824 que incluía naquela época a atual

5 Não é objetivo deste artigo discutir as diferenças em profundidade entre as diferentes concepções teóricas do neoinstitucionalismo; nosso propósito é tão somente demarcar o debate para, na sequência, dialogarmos com as posições teóricas do culturalismo. Certamente, Douglass North (200I) é um dos grandes representantes teóricos deste neoinstitucionalismo americano na contemporaneidade. Para uma discussão mais aprofundada sobre o culturalismo e o institucionalismo, ver Baquero (2013). 
cidade de Novo Hamburgo, emancipada em 5 de abril de 1927. A partir da segunda metade do século XX, há um crescimento vertiginoso dos municípios, chegando-se a 496.

Estas emancipaçóes podem ser explicadas por duas razóes básicas, uma pela necessidade que os governos estaduais tinham em garantir e obter maior representatividade na distribuição dos recursos federais e outra pelas demandas locais, ou seja, pelo crescimento demográfico, pelas necessidades de melhorias na infraestrutura urbana, na qualificaçáo dos serviços públicos e disputas políticas locais (SIENDEBERG, 2003). Neste sentido, as emancipaçôes geraram situaçóes novas, organizaram estas localidades com suas leis orgânicas, aproximando estas comunidades de sua estrutura estatal e canalizando recursos para a regiáo. Estes entáo novos municípios colaboraram de alguma forma para a satisfação dos cidadãos com o desempenho das instituiçóes do Estado, uma vez que auxiliaram na organizaçáo e aplicaçáo dos recursos públicos, através de suas destinaçóes orçamentárias. Contudo, não são somente estas variáveis institucionais (municípios, leis orgânicas, orçamentos) que concorrem para explicar o desempenho dos governos e o desenvolvimento regional. Invertendo o polo desta primazia, Robert Putnam (2000), por exemplo, vai argumentar em defesa da cultura política (comunidade cívica) como fator de determinaçáo do desenvolvimento político, social e econômico de uma regiáo, em detrimento dos aspectos institucionais propriamente ditos.

\section{Políticas públicas e a primazia da cultura}

Para este autor, que pensa a política "de baixo para cima", o importante a investigar sáo os pressupostos indispensáveis para que a democracia responda aos desafios contemporâneos. Assim sendo, uma das questóes centrais que o autor irá indagar-se é por que alguns governos democráticos têm um bom desempenho institucional e outros náo?

Perseguindo esta questáo, o autor analisou vinte anos da história política da Itália, demonstrando que este país apresenta grande diferença regional tanto ao Norte em Seveso, por exemplo, quanto ao Sul do país em Pietraportesa. De uma localidade a outra existe um movimento da modernidade capitalista industrial, em alguns casos pós-industrial, ao sul tradicional e agrícola. Estas diferenças entre estes dois extremos necessitaram da ajuda de reformas políticas para resolver seus problemas de administraçáo pública, posto que na 
década de 1970 criaram-se diversos governos regionais procurando descentralizar a administraçáo política italiana.

Foram criadas vinte regióes idênticas quanto aos seus poderes, entretanto, os desempenhos destas regióes foram muito diferentes. Como explicar esta diferença? O autor procura testar sua hipótese de que a cultura política, as tradiçóes cívicas é que determinam o desenvolvimento socioeconômico de uma regiáo e nela, o capital social. Para Putnam (2000), capital social sáo práticas sociais, normas e relaçóes de confiança que existem entre cidadáos numa determinada sociedade, bem como sistemas de participaçâo e associaçáo que estimulam a cooperaçáo. Quanto maior e mais rico for o número de possibilidades associativas numa sociedade, maior será o volume de capital social. Este por sua vez irá influenciar, por exemplo, no tamanho das empresas locais; em outras palavras, quanto maior o volume de capital social em uma determinada sociedade, maior será o tamanho e o desenvovimento destas empresas (FUKUYAMA, 1996). Em países com parco capital social, o Estado tende a "suprir" esta defecção criando empresas estatais. Assim, o autor argumenta em sua análise das regióes italianas que se formaram dois sistemas sociais equilibrados na Itália, no norte, de comunidade cívica, um equilíbrio virtuoso, ou seja, cooperaçáa, confiança e reciprocidade com menor intervençáo do Estado e o sul, náo cívico, um equilíbrio vicioso de deserção, desconfiança, omissáo e exploraçáo com maior intervenção do Estado.

Aplicando esta perspectiva teórica ao caso do Rio Grande do Sul, Bandeira (2003) estabelece uma diferença regional no estado muito semelhante ao que Putnam (2000) fez na Itália. Como uma primeira aproximação, haveria uma diferença entre o "Norte colonial", cuja "matriz é italiana e alemä", com existência de pouca escravidáo e predomínio do minifúndio, em contraste com o "Sul", cuja "matriz é ibera"6, com o predomínio do latifúndio e o uso extensivo da mão de obra escrava.

No que se refere à primeira regiáo, Bandeira (2003) ressalta que estas zonas coloniais de imigração alemã e italiana estão dotadas de mais CS do que

6 Quando nos referimos à "matriz ibera" ou "tradição ibérica", estamos nos reportando às formas hierárquicas, verticais da organização da vida social, assim quando nos referimos à "matriz italiana e alemã ou "imigração italiana e alemã”, estamos fazendo menção à forma horizontal de organização da vida social e não a questões de ordem étnica ou racial. 
as da região sul. Nas primeiras encontramos uma infinidade de associaçóes recreativas, clubes sociais, sociedades de canto, de atiradores e artísticas, bem como uma intensa vida social colaborativa e cooperativa entre os primeiros colonos que aqui chegaram ao século XIX. As estatísticas do período têm apontado que entre os anos de 1824 e 1830 entraram cerca de 5.350 alemáes no estado Rio Grande do Sul, e entre os anos de 1830 e 1889 foram introduzidos mais 20.000 imigrantes que aqui desembarcaram, sendo responsáveis pela criação de 142 colônias alemãs no estado (ANUÁRIO, 2012). Nos municípios que surgiram a partir do desmembramento de Sáo Leopoldo, vê-se um quadro de povoamento semelhante, no qual a composiçáo étnica esteve inicialmente marcada pelos alemáes (WEBER, 2006), como no caso da cidade aqui analisada, Novo Hamburgo. Todavia, deve-se levar em consideraçáo que outros grupos étnicos raciais também compuseram o cenário desta regiáo, especialmente índios, negros, açorianos e luso-brasileiros, muito embora apareçam comumente na bibliografia como agentes de experiências fracassadas (NUNES, 2009). Os dados de nossa pesquisa em 2012 e 2013 desmistificaram a ideia de uma "sociedade alemâ" atualmente nestas localidades, na medida em que apenas 31\% dos hamburgueses se autodeclararam de origem étnica alemá, e em Sáo Leopoldo este percentual ficou ainda menor, em 22\%.

Nestas áreas de imigraçáo, por exemplo, registra-se o traço da cooperação e da solidariedade; um grupo fazia a colheita quando um colono estava doente, assim como a conservaçáo da estrada, bem como os acordos para a construçáo do cemitério, para a construçáo da capela dava-se por iniciativa dos pequenos proprietários rurais locais (DE BONI; COSTA, 1979 apud BANDEIRA, 2003).

Dentro da matriz teórica do capital social, também Monastério (2003) analisa a qualidade das administraçóes municipais no estado do Rio Grande do Sul. Nas localidades, que ele denomina de planalto e serra (utilizando outra divisão territorial, mas referindo-se às zonas de colonizaçáo), há os melhores indicadores de qualidade da administraçáo pública em contraposiçâo às regiôes da campanha (Sul). Em sua análise, na regiâo da campanha, há menor formulaçáo legislativa, menos informatizaçáo, menos conselhos, gasta-se o mínimo previsto na legislaçâo com saúde e educação, ao passo que na serra e no planalto estes indicadores tendem a ser melhores pela dotaçáo de capital social. 
Nesta perspectiva, há forte inclinaçâo patrimonialista e personalista na regiáo da campanha, no sul do estado, que teve uma "tradição ibérica" mais notada. Lá, há uma acentuaçáo singular enérgica do afetivo, do irracional, do passional, ou antes, uma atrofia das qualidades como coordenadores, disciplinadores e racionalizadores (HOLANDA, 1981 apud BANDEIRA, 2003). Somado a este traço, as longínquas distâncias entre os agrupamentos, as escassas instituiçóes de solidariedade social, de cooperaçấo, dão ao impulso solidário entre vizinhos, a caracterização da afetividade e da delicadeza moral, náo da solidariedade que visa obter uma utilidade comum (VIANNA, 1999 apud BANDEIRA, 2003). ${ }^{7}$

Boschi (1999), comparando duas capitais brasileiras, Belo Horizonte e Salvador, no que diz respeito às suas experiências de governança, ou seja, na transparência na formulaçáo e eficácia de políticas públicas, argumenta que a principal diferença entre elas está relacionada à existência de capital social. No primeiro caso, há mais estruturas horizontais e capital social, que ajudam a reduzir as práticas clientelísticas e centralizadas de administraçáo, ao passo que em Salvador estas práticas são muito mais abundantes e, portanto, deletérias à administração local, onde há menos capital social e estruturas horizontais de organizaçáo. Fernandes (2001) também demonstrou como a produçáo de laços de confiança e fidelidade mútua facilita a cooperaçáo social, aumentando o desempenho e a responsabilidade dos governos e das instituiçóes democráticas.

Em outro trabalho comparando as cidades de Caxias do Sul e Pelotas, demonstramos que o Sistema Único de Saúde Odontológico (SUS), implantado igualmente em ambas as cidades, mostrou um melhor desempenho na cidade de Caxias do Sul (matriz italiana/minifúndio/imigração) do que na cidade de Pelotas (matriz ibera/latifúndio/escravidáo), cidade esta menos detentora de capital social do que Caxias (SANTOS et al., 2010). De fato, a escravidão e o latifúndio do passado constituíram-se numa instituição deletéria à construçáo de solidariedades horizontais ainda no presente, impactando sobre as políticas públicas.

7 É importante ressaltar que há estudos sobre o sul do estado que não autorizam uma visão estanque e caricata entre norte e sul, no sentido deste último constituir-se num "deserto social", existiria formas de sociabilidade nas maiores cidades do sul. Na virada do século XX. Bagé é um exemplo desta proliferação associativista (BANDEIRA, 2003). 


\section{Um sinergismo possível}

A primazia da cultura política, portanto da importância do capital social para explicar o desempenho institucional de uma regiáo, conforme Putnam (2000), Bandeira (2001), Monastério (2003), Boschi (1999) e Bastos et al. (2010), constitui-se em importante variável para compreender-se o desenvolvimento econômico e o desempenho das políticas públicas, como acompanhamos. Contudo, entendemos que a cultura política náo pode ser compreendida separadamente, mas deve ser integrada numa perspectiva sinergética que combine instituiçóes e cultura, como "circuitos endógenos de mútua determinaçáo" (SANTOS et al., 2010). Nesta encruzilhada da teoria culturalista e institucional (formal versus informal), o Banco Mundial tem proposto uma abordagem semelhante também, partindo do princípio de que instituiçóes formais necessitam do envolvimento e do compromisso social a fim de que náo se tornem instituiçóes vazias e inúteis (BAQUERO, 2013).

Pensamos como Przeworski (2005) que, muito embora haja de fato uma contribuição significativa para as Ciências Sociais destas perspectivas teóricas, a procura de uma determinaçáo primordial para o desenvolvimento e, particularmente aqui, para o desempenho de políticas, é um equívoco epistemológico. Ou seja, procurar quem determina o quê.

Náo há esta linearidade, para Przeworski (2005), nada pode ser a causa primordial do desenvolvimento, as instituiçóes ou mesmo as dinâmicas socias. As instituiçóes não são uma causa mais profunda, exógena que determina sempre a provisáo de "fatores e seus usos", mas os próprios fatores, a cultura política, por exemplo, em nosso caso, podem afetar o crescimento e a ulterior prosperidade de uma regiāo, que por sua vez pode afetar a evolução das instituições. Quem criou as instituiçôes? Elas certamente não se criaram sozinhas, além do que estas instituiçóes podem ter efeitos diferentes, dependendo do contexto. O que o autor está chamando a atençáo é para o fato de que as instituiçôes são mutuamente interdependentes e evoluem conjuntamente com as dinâmicas sociais.

Então, as instituiçóes não deixam de apresentar uma importância fundamental para o desenvolvimento e para o próprio desempenho dos governos e de suas políticas. Dito isso, deparamo-nos com a dificuldade de estabelecer a "estrutura causal" sobre o desempenho dos governos. Seria a variável 
instituição ou a variável cultura política que determina o desempenho satisfatório dos governos? A soluçáo para a dicotomia de quem veio primeiro parece náo contribuir efetivamente para a soluçáo do problema da eficiência das organizaçóes.

Seguindo a sugestáo de Przeworski (2005), optamos em compreender estas diferentes variáveis como "circuitos endógenos de mútua determinação e reforçamento". Nesta perspectiva, abrindo máo de buscar identificar o que é endógeno ou exógeno ou o que determina o quê no desempenho dos governos, optamos em identificar apenas seus recíprocos impactos na sociedade, num modelo mais flexível que combine um sinergismo possível entre instituiçóes e cultura política. Aqui, certamente, seguimos Weber (1999), para o qual não há monocausalidade para os fenômenos sociais, cabendo a atitude científica buscar mensurar estas impactantes variáveis para o desempenho institucional.

A partir do exposto e no intuito de mensurarmos o impacto das determinaçóes institucionais, legais em Novo Hamburgo e São Leopoldo, analisamos as dotaçóes orçamentárias nestas cidades e o grau de satisfação de seus usuários em relaçáo aos serviços básicos prestados pelo município como um primeiro movimento na direçáo desta variável.

Na Tabela 1, podemos observar que os gastos com educação, saúde, obras, esporte, lazer e cultura e segurança em 2012 foram diferentes nas duas cidades analisadas em termos absolutos ${ }^{8}$. Enquanto Novo Hamburgo gastou um total de R \$ 457.100.441,98 nas suas diferentes áreas, Sáo Leopoldo gastou $\mathrm{R} \$ 323.749 .266,48$, um número relativamente menor. O orçamento de Novo Hamburgo foi maior do que o orçamento de Sáo Leopoldo. Muito embora a quantia dos gastos totais seja diferente entre as cidades devido a suas receitas e populaçóes diferentes, observamos que os dois principais gastos per capita em ambas as cidades estão relacionados com a educaçáo (R \$ 527,33 e $\mathrm{R} \$ 531,22$ respectivamente) e a saúde ( $\mathrm{R} \$ 498,47$ e $\mathrm{R} \$ 251,83)$. Isto reflete, de certa forma, o artigo 212 da Constituiçáo Federal, que obriga os municípios a aplicarem anualmente "vinte e cinco por cento, no mínimo, da receita resultante de impostos, compreendida e proveniente de transferências na manutençáo e desenvolvimento do ensino".

8 Estamos tomando aqui as áreas de educação, saúde, obras, segurança e esporte e lazer como variáveis institucionais, independentes, que produzem um efeito a partir de seus investimentos orçamentários. 
Tabela I - Gastos comparativos por área nos municípios de Novo Hamburgo e São Leopoldo

\begin{tabular}{lcccc}
\hline \multirow{2}{*}{ Área } & \multicolumn{2}{c}{ Novo Hamburgo } & \multicolumn{2}{c}{ São Leopoldo } \\
\cline { 2 - 5 } & Total (R\$) & Per capita(R\$) & Total (R\$) & Per capita(R\$) \\
\hline Educação & $126.422 .094,96$ & 527,33 & $114.535 .503,86$ & 531,22 \\
Saúde & $119.503 .734,85$ & 498,47 & $54.297 .004,70$ & 251,83 \\
Obras & $34.076 .709,60$ & 142,14 & $7.151 .648,69$ & 33,16 \\
Segurança & $16.794 .902,53$ & 70,05 & $10.810 .290,34$ & 50,13 \\
Esp. Lazer e Cult. & $8.299 .853,88$ & 34,62 & $4.719 .596,19$ & 21,88 \\
Gasto Total & $457.100 .441,98$ & $1.906,66$ & $323.749 .266,48$ & $1.501,57$ \\
Número de & & & & \\
Habitantes & 239.738 & & & \\
\hline
\end{tabular}

Fonte: Tribunal de Contas do Estado do Rio Grande do Sul (TCE) e Fundação de Economia e Estatistica (FEE) Ano: 2012

No caso da saúde, de acordo com a Emenda Constitucional 29, de 13 de setembro de 2000 , os municípios devem aplicar $15 \%$ do produto da arrecadaçáo dos impostos, como forma de garantir os recursos mínimos destinados a esta área. Assim, a saúde vem em segundo lugar nos gastos nas cidades, depois da educação. Destacamos que se trata de recursos mínimos, não impedindo os executivos de destinarem percentuais superiores nas leis orçamentárias.

No que se refere aos gastos totais, como podemos observar ainda na Tabela 1, Novo Hamburgo gastou o equivalente a $26 \%$ na área da saúde ( $\mathrm{R} \$ 119.503 .734,85)$, ao passo que Sáo Leopoldo 16\% (R\$ 54.297.004,70). Complementar a esta observaçáo, na Tabela 2 podemos verificar que o município de Novo Hamburgo gastou por habitante o valor de $\mathrm{R} \$ 498,47$, quase o dobro que o município de Sáo Leopoldo, $\mathrm{R} \$ 251,83$, o que se reflete, de certa forma, numa avaliaçáo positiva de $20 \%$ da populaçáo que consideraram a saúde boa na cidade. Em São Leopoldo, apenas $10 \%$ avaliaram a saúde em boa, ou seja, a metade do percentual de Novo Hamburgo, seguindo quase que 
lineramente o corte da metade dos gastos per capita nesta área ( $\mathrm{R} \$ 251,83)$. $\mathrm{Na}$ área da educaçáo, notamos que os gastos per capita em ambas as cidades ( $\mathrm{R}$ \$ 527,33 e R\$ 531,00) sáo muito próximos, ficando a avaliaçáo "boa" em Novo Hamburgo no percentual de 48\% e São Leopoldo em 35\%, ligeiramente menor.

Tabela 2 - Avaliação de satisfação com as políticas públicas do município de Novo Hamburgo e gastos por habitante ${ }^{9}$

\begin{tabular}{ccccc}
\hline \multirow{2}{*}{ Área } & \multicolumn{2}{c}{ Novo Hamburgo } & \multicolumn{2}{c}{ São Leopoldo } \\
\cline { 2 - 5 } & $\begin{array}{c}\text { Avaliação } \\
\text { Bom (\%) }\end{array}$ & $\begin{array}{c}\text { Per } \\
\text { capita(R\$) }\end{array}$ & $\begin{array}{c}\text { Avaliação } \\
\text { Bom (\%) }\end{array}$ & $\begin{array}{c}\text { Per } \\
\text { capita(R\$) }\end{array}$ \\
\hline Educação & 48 & 527,33 & 35 & 531,22 \\
Saúde & 20 & 498,47 & 10 & 251,83 \\
Obras & 55 & 142,14 & 60 & 33,16 \\
Segurança & 26 & 70,05 & 22 & 50,13 \\
Esp., Lazer e Cult. & 32 & 34,62 & 32 & 21,88 \\
\hline
\end{tabular}

Fonte: Projeto de Pesquisa Capital Social e Políticas Públicas/CPP FEEVALE, Tribunal de Contas do Estado do Rio Grande do Sul (TCE) e Fundação de Economia e Estatistica (FEE). Ano: 2012

Com exceção da educação, Novo Hamburgo investiu mais por habitante em todas as áreas avaliadas, o que parece refletir na maior satisfaçáo com as políticas municipais de maneira geral. Das cinco áreas avaliadas, em quatro delas a satisfação é maior (educaçáo; saúde; segurança; esporte, lazer e cultura). Em Sáo Leopoldo, com menores investimentos, há menor satisfaçáo com as diferentes áreas, pois apenas uma delas, as obras, com 60\%, supera Novo Hamburgo (55\%), conforme Tabela 2. Assim, percebe-se que, de maneira geral, na cidade de Novo Hamburgo a populaçáo recebeu mais investimentos per capita do que na cidade de Sáo Leopoldo, o que pode ser um dos fatores explicativos para a maior satisfaçáo dos munícipes daquela cidade em relaçáo às instituiçôes prestadoras de seus serviços.

9 A variável utilizada para medir a satisfação com as políticas públicas foram: Como o senhor avalia a qualidade dos serviços públicos na sua cidade nas áreas de educação, saúde, obras, segurança, esporte e lazer? Ótimo, bom, regular, ruim, péssimo. 
Os dados analisados evidenciam a importância do volume de investimentos em si e dos previstos em lei, que aplicados de igual forma em ambas as cidades, como vimos, produziram certos resultados, que muito embora com alguma diferença demonstram a importância dos orçamentos e dos gastos de uma maneira geral.

Contudo, ainda permanece outra questáo: $O$ investimento público é a única variável que explica os níveis de satisfação com os serviços prestados pelos municípios nestas cidades? Se as dotaçóes orçamentárias, os investimentos, os gastos totais ajudam na compreensão de parte deste fenômeno, por outro lado não ajudam a explicar, por exemplo, porque a saúde, com a segunda dotaçáo per capita nas cidades, obteve o primeiro lugar na insatisfaçáo destas populaçóes. Todavia, procurando evitar a monocausalidade, pensamos que, para além do investimento dos respectivos orçamentos das cidades, a qualidade do tecido social em que eles sáo aplicados ajuda a explicar os níveis de satisfação destas populaçóes com os serviços públicos prestados tanto em Novo Hamburgo como em Sáo Leopoldo. Em outras palavras, os níveis de capital social que temos nestas cidades podem estar permitindo um melhor funcionamento destas instituiçóes prestadoras de serviços públicos e consequentemente uma maior satisfação dos munícipes com estes.

Sendo assim, torna-se importante verificarmos os níveis de capital social comparativamente entre as cidades, ou seja, os níveis de confiança interpessoal, bem como sua relaçáo com o funcionamento das instituiçóes, consequentemente das políticas públicas.

No Gráfico 1, podemos observar que os índices de capital social na cidade de Novo Hamburgo apresentaram 1\% de alto, 28\% de médio e 71\% de baixo, contra $0 \%$ de alto em Sáo Leopoldo, $22 \%$ de médio, subindo para $78 \%$ de baixo. A cidade de Novo Hamburgo apresenta uma leve tendência de maior capital social entre seus habitantes do que Sáo Leopoldo. 


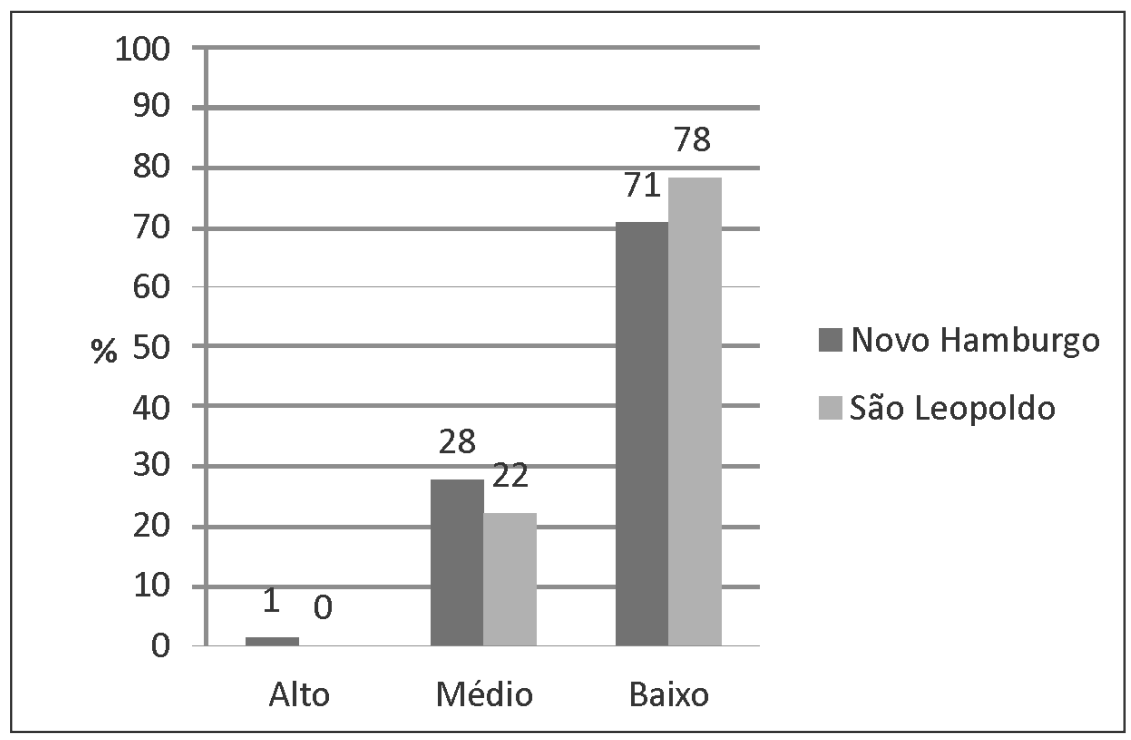

\title{
Gráfico I - Índice de capital social (ICS) dos municípios de Novo Hamburgo e São Leopoldo ${ }^{10}$
}

\author{
Fonte: Projeto de Pesquisa Capital Social e Políticas \\ Públicas/CPP FEEVALE. $N=613 \mathrm{~N}=600$. Ano: 20/2; 2013
}

10 Este índice de capital social (ICS) foi baseado em Baquero (2007) e construído de forma idêntica para os dois COREDES a partir da seleção de 9 questões relativas ao capital social. São elas: "Em termos gerais, o senhor diria que se pode confiar nas pessoas ou não se pode confiar nas pessoas?" Sim (peso 2), Não (peso 0); "Gostaria de saber se o senhor confia muito (peso 2), pouco (peso 1) ou não confia (peso 0) na: igreja, família, vizinhos, associações comunitárias, sindicatos"; "O senhor costuma participar de: partidos políticos, reuniōes políticas, comícios, associações comunitárias, associações religiosas, associações sindicais, conselhos populares, ONGs, orçamento participativo, abaixo-assinados, manifestações ou protestos, greves, ocupação de terrenos ou prédios públicos, outros" Sim (peso 2), Não (peso 0); "Nos últimos anos, o senhor tentou resolver algum problema local do bairro/comunidade junto com outras pessoas? Sim (peso 2), Não (peso 0): "Dentre os grupos que eu vou mencionar, quais deles existem no seu bairro: grupo político, grupo ou associação cultural, grupo educacional, grupo esportivo, grupo de jovens, ONG ou grupo cívico, grupo baseado na comunidade étnica, grupos de mulheres, outro" Sim (peso 2), Não (peso 0); "Atualmente o senhor participa de algum grupo ou organização?" Sim (peso 2), Não (peso 0); "Se precisasse viajar por um ou dois dias, o senhor poderia contar com vizinhos para cuidar da sua casa elou filhos?" Sim (peso 2). Provavelmente (peso I). Não (peso 0): "Em uma situação de emergência como a doença de um familiar ou perda de emprego, o senhor receberia ajuda:" familiares (peso 0), vizinhos (peso 2), colegas de trabalho (peso 2); "Se um projeto da comunidade não the beneficia diretamente, mas pode beneficiar outras pessoas do seu bairro, o senhor contribui pra este projeto?" Sim (peso 2), Não (peso 0). Foram propostos pesos I e 2 para os itens que positivamente afirmavam a cooperação, reciprocidade, participação e peso 0 para a negação destas características. Para o cálculo do ICS é realizada a soma das pontuações obtidas em cada questão, seguido do cálculo da razão entre a soma obtida e a maior pontuação que é possivel obter no teste. Este índice está ancorado teoricamente no conceito de capital social de Putnam(2000), para o qual relações de confiança interpessoal, reciprocidade, cooperação, participação e niveis de organização são indicadores da existência de capital social em uma sociedade. 
Para melhor exemplificarmos nosso índice de capital social, e a título de ilustração das questôes que compóem este indicador, no Gráfico 2, como podemos observar, $69 \%$ dos hamburguenses e leopoldenses responderam que "não se pode confiar nas pessoas", e apenas $24 \%$ em Novo Hamburgo responderam que "se pode confiar nas pessoas", contra 17\% em Sáo Leopoldo.

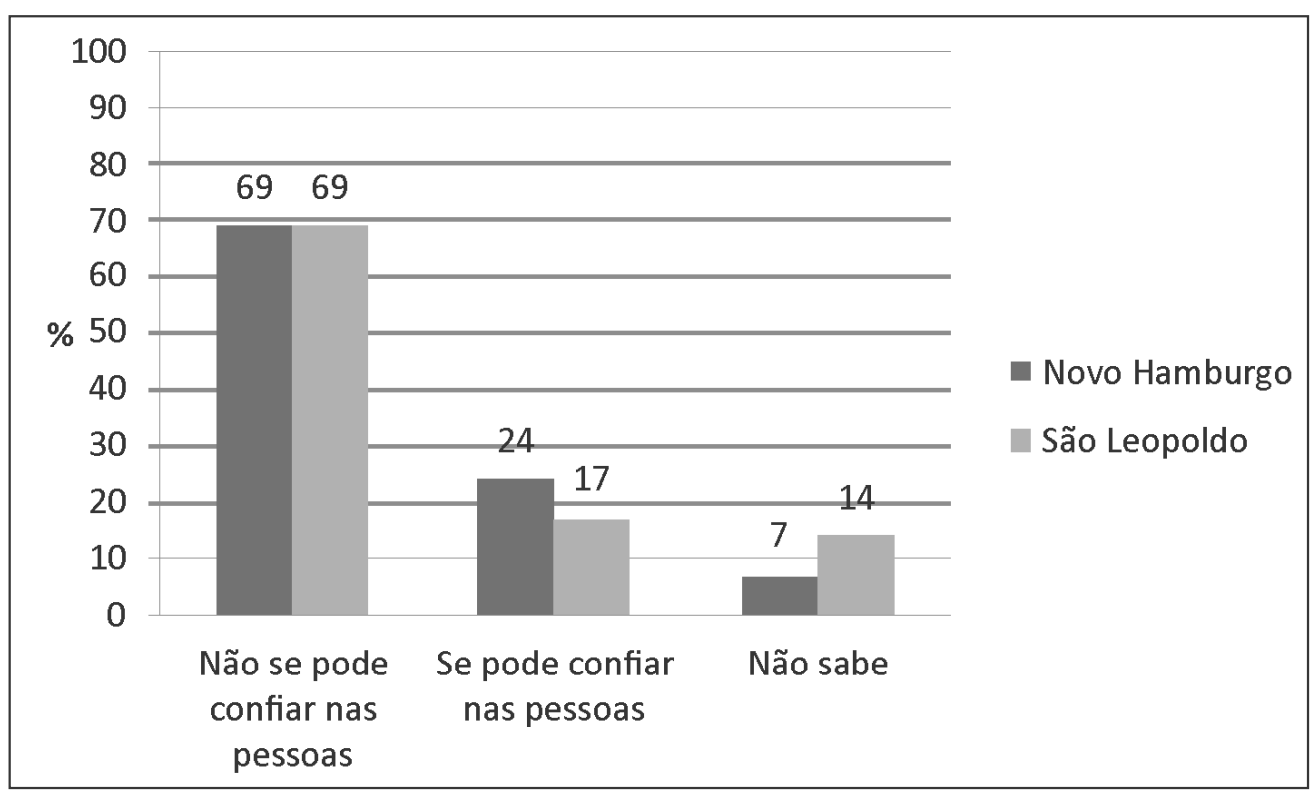

Gráfico 2 - Confiança interpessoal dos municípios de Novo Hamburgo e São Leopoldo

Fonte: Projeto de Pesquisa Capital Social e Políticas Públicas/CPP FEEVALE. N=6/3 N=600. Ano: 20/2; 20/3

Entretanto, no Gráfico 3, quando perguntamos para a população: "Se precisasse viajar por um ou dois dias, o senhor (a) poderia contar com a ajuda de vizinhos para cuidar de sua casa e/ou dos seus filhos?", em Novo Hamburgo $77 \%$ responderam afirmativamente que "sim ou provavelmente" e $17 \%$ que não poderiam; em Sáo Leopoldo, o percentual sobe ligeiramente para $83 \%$ que responderam afirmativamente que "poderiam contar com a ajuda dos vizinhos ou provavelmente” e 12\% que nâo poderiam. Aqui há uma leve inclinaçáo de capital social mais favorável a São Leopoldo. 


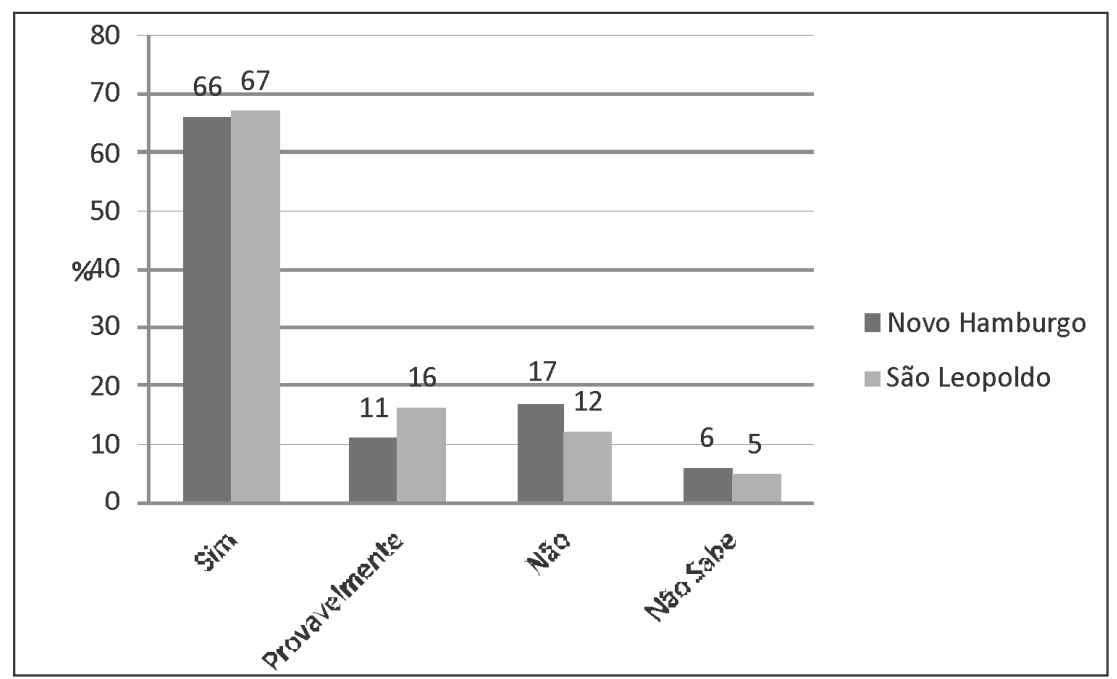

Gráfico 3 - Contar com a ajuda de vizinhos

Fonte: Projeto de Pesquisa Capital Social e Políticas

Públicas/CPP FEEVALE. $N=613 \mathrm{~N}=600$. Ano: $2012 ; 2013$

Quando aprofundamos a pergunta sobre a confiança nos vizinhos e nas associaçóes comunitárias, no Gráfico 4, Novo Hamburgo e São Leopoldo ficam empatados, com $64 \%$ dos hamburguenses e leopoldenses que afirmam que "confiam muito ou confiam nos vizinhos", contra 13\% dos hamburguenses e $12 \%$ dos leopoldenses que afirmaram confiar pouco ou náo confiar.

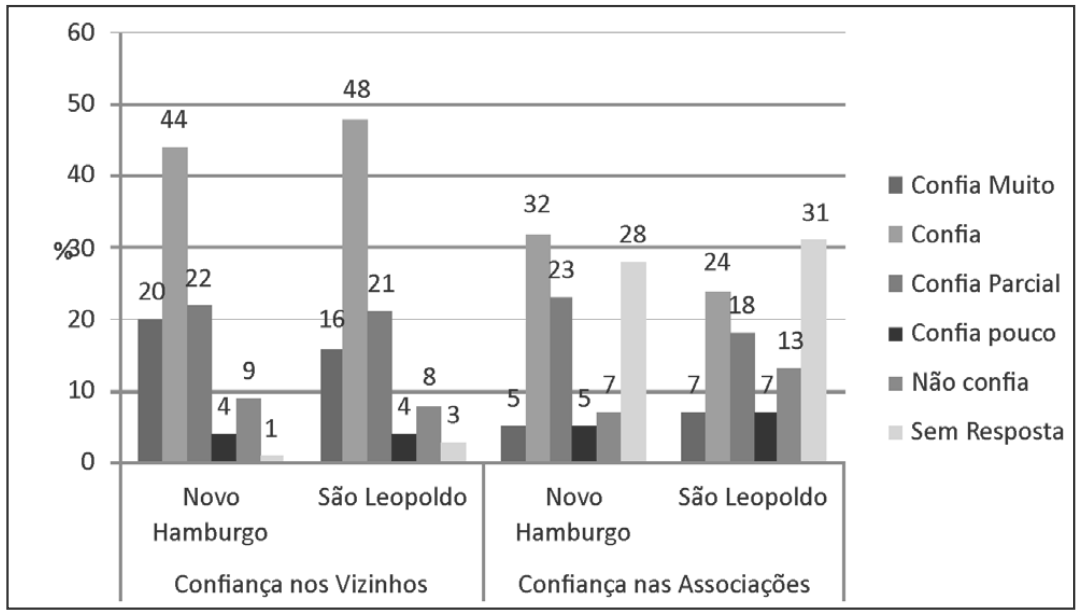

Gráfico 4 - Nível de confiança nos vizinhos e nas associações dos municípios de Novo Hamburgo e São Leopoldo

Fonte: Projeto de Pesquisa Capital Social e Políticas Públicas/CPP FEEVALE. $N=613 \mathrm{~N}=600$. Ano: 20/2; 2013 
Em relação às associaçōes comunitárias, ainda no Gráfico 4, Novo Hamburgo assume certa vantagem quando $37 \%$ dos hamburguenses responderam "confiar muito ou confiar" nas associaçóes comunitárias, contra 31\% dos leopoldenses. Nesta mesma questão, $12 \%$ dos moradores de Novo Hamburgo afirmaram "confiar pouco ou não confiar nas associaçóes comunitárias", ao passo que em Sáo Leopoldo este percentual subiu para $20 \%$.

Uma vez constatada esta leve tendência de maior volume de capital social em Novo Hamburgo na comparação com Sáo Leopoldo, nos diferentes gráficos, particularmente cristalizado no Gráfico 1, no índice de capital social (ICS), foi preciso verificar o impacto deste capital social sobre as políticas municipais.

De maneira geral, quando os entrevistados responderam sobre a qualidade dos serviços públicos em sua cidade, $27 \%$ em Novo Hamburgo avaliaram em ótimo ou bom, contra $27 \%$ em ruim ou péssimo, conforme Tabela 3. Em Sáo Leopoldo, apenas 15\% avaliaram em ótimo ou bom, contra 37\% em ruim ou péssimo. O município de Sáo Leopoldo tende a avaliar os serviços públicos de maneira mais negativa do que Novo Hamburgo.

Tabela 3 - Avaliação geral da qualidade dos serviços públicos em sua cidade \%

\begin{tabular}{ccc}
\hline & Novo Hamburgo \% & São Leopoldo \% \\
\hline Ótimo & 2 & 1 \\
Bom & 25 & 14 \\
Regular & 44 & 42 \\
Ruim & 14 & 20 \\
Péssimo & 13 & 17 \\
NS/NR & 2 & 6 \\
Total & 100 & 100 \\
\hline
\end{tabular}

Fonte: Projeto de Pesquisa Capital Social e Políticas Públicas/CPP FEEVALE. N =613 N=600. Ano: 2012;2013

Observando-se a Tabela 4, quando os entrevistados são convidados a avaliar os serviços públicos por área em Novo Hamburgo, podemos explicar a avaliaçáo negativa da qualidade dos serviços públicos na cidade (os $27 \%$ em ruim e péssimo da Tabela 3) pelas avaliaçóes de ruim e péssimo nas áreas da 
saúde 55\%, 47\% segurança e 27\% esporte, lazer e cultura. Por outro lado, os percentuais positivos da qualidade dos serviços públicos da cidade, 27\%, podem ser explicados pelas avaliaçóes positivas de bom e ótimo nas áreas de habitação (57\%), saneamento (54\%) e transporte (53\%). Quando os entrevistados são convidados a dizer em nossa pesquisa qual o maior problema do município, cerca de 40\% deles responderam afirmativamente ser a saúde.

Tabela 4 - Qualidade dos serviços públicos em Novo Hamburgo por área \%

\begin{tabular}{lccccccc}
\hline & Péssimo & Ruim & Regular & Bom & Ótimo & N/R & Total \\
\hline Saúde & 35 & 20 & 21 & 18 & 2 & 4 & 100 \\
Segurança Pública & 26 & 21 & 26 & 24 & 2 & 2 & 100 \\
Esporte/Lazer/Cultura & 12 & 15 & 26 & 30 & 2 & 15 & 100 \\
Saneamento Básico & 6 & 8 & 27 & 51 & 3 & 5 & 100 \\
Transporte & 5 & 10 & 18 & 49 & 4 & 14 & 100 \\
Educação & 3 & 5 & 30 & 44 & 5 & 13 & 100 \\
Habitação & 3 & 7 & 30 & 52 & 5 & 3 & 100 \\
\hline
\end{tabular}

Fonte: Projeto de Pesquisa Capital Social e Políticas Públicas/CPP FEEVALE. $N=6 / 3$. Ano: 2012

$\mathrm{Na}$ cidade de Sáo Leopoldo, o percentual de ótimo ou bom na avaliaçáo geral da qualidade dos serviços públicos desceu para 15\%, cerca de $10 \%$ a menos do que Novo Hamburgo, conforme a Tabela 3. As avaliaçóes de ruim ou péssimo subiram para $37 \%$, um percentual $10 \%$ a mais do que o de Novo Hamburgo. O que está sustentando os $15 \%$ das avaliaçóes positivas em São Leopoldo? Muito provavelmente o transporte (63\%), a habitaçáo (61\%) e o saneamento $(58 \%)$ de bom e ótimo foram as políticas públicas melhor avaliadas e que mais contrastaram com o polo negativo, contribuindo assim para o resultado da pesquisa, conforme Tabela 5. Todavia, o polo negativo, os 37\% são sustentados pelas avaliaçóes negativas (péssimo e ruim) nas áreas de saúde (65\%), segurança (50\%) e em menor grau esporte, lazer e cultura (22\%).

Quando os entrevistados sáo convidados a dizer qual o maior problema do município em Sáo Leopoldo, 54\% deles responderam espontaneamente ser a saúde, percentual maior do que o de Novo Hamburgo (40\%). 
Tabela 5 - Qualidade dos serviços públicos em São Leopoldo por área \%

\begin{tabular}{lccccccc}
\hline & Péssimo & Ruim & Regular & Bom & Ótimo & N/R & Total \\
\hline Saúde & 38 & 27 & 22 & 10 & 1 & 2 & 100 \\
Segurança Pública & 24 & 26 & 27 & 21 & 1 & 1 & 100 \\
$\begin{array}{l}\text { Esporte/Lazer/ } \\
\text { Cultura }\end{array}$ & 8 & 14 & 24 & 31 & 1 & 22 & 100 \\
$\begin{array}{l}\text { Saneamento Básico } \\
\text { Transporte }\end{array}$ & 4 & 12 & 24 & 54 & 4 & 2 & 100 \\
Educação & 3 & 5 & 17 & 60 & 3 & 12 & 100 \\
Habitação & 7 & 10 & 35 & 33 & 1 & 14 & 100 \\
\hline
\end{tabular}

Fonte: Projeto de Pesquisa Capital Social e Políticas Públicas/CPP FEEVALE. N=600. Ano: 2013

Avançando em nosso objetivo central, qual seja, de avaliarmos o impacto do capital social sobre as políticas públicas municipais, foi preciso investigar exatamente a relação existente entre as variáveis de satisfação com a qualidade dos serviços públicos municipais de maneira geral com as variáveis de capital social. Assim, procuramos cruzar a satisfaçáo dos munícipes em relaçáo à qualidade dos serviços públicos com nosso índice de capital social do Gráfico 1, a fim de comprovarmos nossa hipótese de trabalho de que o capital social, próprio da cultura política local existente nas cidades em tela, constitui-se num aliado às instituiçóes políticas, pois ele favorece positivamente a avaliaçáo do desempenho das políticas públicas municipais.

Neste sentido, utilizamos dois testes náo paramétricos, o teste Kruskal-Wallis e o teste Mann-Whitney, para avaliar se existem diferenças significativas na satisfaçáo dos serviços públicos quando comparamos os três níveis do indicador de capital social.

Como podemos observar no Quadro 1, na variável saúde, quando aumentam os indicadores de capital social de 1 (baixo), 2 (médio) e 3 (alto), também aumentam os escores de satisfação de 290,69 no nível 1, para 307,73 no nível 2, caindo para 235,00 no nível 3. Na educaçáo, também se repete o mesmo fenômeno. Quando aumentam os escores de capital social de 1 para 2 , temos 256,99 para 284,46, e no escore 3 temos 263,60. Todavia, quando 
observamos a área do esporte, lazer e cultura, há certa linearidade, na medida em que aumentam os indicadores de capital social de 1,2 e 3 , aumentam os escores respectivamente 252,$64 ; 282,23 ; 295,90$. O mesmo vai ocorrer com o transporte e a segurança pública.

Quadro I - Teste Kruskal-Wallis para comparação da satisfação dos serviços públicos entre os níveis do indicador de capital social (Novo Hamburgo)

\begin{tabular}{|c|c|c|c|c|c|}
\hline & INDCOD & $\mathbf{N}$ & Mean Rank & $\begin{array}{c}\text { Chi- } \\
\text { Square }\end{array}$ & P-VALUE \\
\hline \multirow{4}{*}{ Saúde } & Baixo & 419 & 290,69 & \multirow{4}{*}{1,94} & \multirow{4}{*}{0,38} \\
\hline & Médio & 165 & 307,73 & & \\
\hline & Alto & 5 & 235,90 & & \\
\hline & Total & 589 & & & \\
\hline \multirow{4}{*}{ Educação } & Baixo & 371 & 256,99 & \multirow{4}{*}{4,22} & \multirow{4}{*}{0,12} \\
\hline & Médio & 153 & 284,46 & & \\
\hline & Alto & 5 & 263,60 & & \\
\hline & Total & 529 & & & \\
\hline \multirow{4}{*}{ EspLazCult } & Baixo & 368 & 252,64 & \multirow{4}{*}{4,73} & \multirow{4}{*}{0,09} \\
\hline & Médio & 149 & 282,23 & & \\
\hline & Alto & 5 & 295,90 & & \\
\hline & Total & 522 & & & \\
\hline \multirow{4}{*}{ Transporte } & Baixo & 374 & 261,14 & \multirow{4}{*}{4,48} & \multirow{4}{*}{0,11} \\
\hline & Médio & 156 & 281,57 & & \\
\hline & Alto & 5 & 358,00 & & \\
\hline & Total & 535 & & & \\
\hline \multirow{4}{*}{ Segurança } & Baixo & 436 & 300,05 & \multirow{4}{*}{5,11} & \multirow{4}{*}{0,08} \\
\hline & Médio & 168 & 313,10 & & \\
\hline & Alto & 5 & 464,30 & & \\
\hline & Total & 609 & & & \\
\hline
\end{tabular}


(Continuação)

\begin{tabular}{|c|c|c|c|c|c|}
\hline & INDCOD & $\mathbf{N}$ & Mean Rank & $\begin{array}{l}\text { Chi- } \\
\text { Square }\end{array}$ & P-VALUE \\
\hline \multirow{4}{*}{ Saneamento } & Baixo & 420 & 293,36 & \multirow{4}{*}{0,08} & \multirow{4}{*}{0,96} \\
\hline & Médio & 163 & 297,38 & & \\
\hline & Alto & 5 & 296,20 & & \\
\hline & Total & 588 & & & \\
\hline \multirow{4}{*}{ Habitação } & Baixo & 425 & 296,03 & \multirow{4}{*}{0,26} & \multirow{4}{*}{0,88} \\
\hline & Médio & 162 & 298,74 & & \\
\hline & Alto & 5 & 263,90 & & \\
\hline & Total & 592 & & & \\
\hline
\end{tabular}

Fonte: Projeto de Pesquisa Capital Social e Políticas Públicas/CPP FEEVALE. N =613

Estas evidências nos levaram a aplicar o teste de Kruskal-Wallis para verificarmos se havia significância entre as variáveis cruzadas. Nestes dois últimos casos, os valores do p-value ficaram muito próximos da significância estatística, como podemos notar, 0,78 na segurança pública e 0,94 no esporte, lazer e cultura. Muito embora este teste tenha nos aproximado de nossa hipótese de trabalho, o número baixo de $\mathrm{N}=5$ nos levou a agruparmos estes casos do nível 3 com o nível 2 que apresentam capital social médio no teste do Quadro 2.

Quadro 2 - Teste Mann-Whitney para comparação da satisfação dos serviços públicos entre os níveis agrupados do indicador de capital social (Novo Hamburgo)

\begin{tabular}{|c|c|c|c|c|c|c|}
\hline & INDMODIF & $\mathbf{N}$ & $\begin{array}{l}\text { Mean } \\
\text { Rank }\end{array}$ & $\begin{array}{l}\text { Sum of } \\
\text { Ranks }\end{array}$ & $\begin{array}{c}\text { Mann- } \\
\text { Whitney U }\end{array}$ & P-VALUE \\
\hline \multirow{3}{*}{ Saúde } & I & 419 & 290,69 & 121799,5 & \multirow{3}{*}{33809,500} & \multirow{3}{*}{0,315} \\
\hline & 2 & 170 & 305,62 & 51955,5 & & \\
\hline & Total & 589 & & & & \\
\hline \multirow{3}{*}{ Educação } & I & 371 & 256,99 & 95345 & & \\
\hline & 2 & 158 & 283,8 & 44840 & & \\
\hline & Total & 529 & & & 26339,000 & 0,043 \\
\hline
\end{tabular}

(Continua) 
(Continuação)

\begin{tabular}{|c|c|c|c|c|c|c|}
\hline & INDMODIF & $\mathbf{N}$ & $\begin{array}{l}\text { Mean } \\
\text { Rank }\end{array}$ & $\begin{array}{l}\text { Sum of } \\
\text { Ranks }\end{array}$ & $\begin{array}{c}\text { Mann- } \\
\text { Whitney U }\end{array}$ & P-VALUE \\
\hline \multirow{3}{*}{ EspLazCult } & I & 368 & 252,64 & 92971,5 & & \\
\hline & 2 & 154 & 282,67 & 43531,5 & & \\
\hline & Total & 522 & & & 25075,500 & 0,030 \\
\hline \multirow{3}{*}{ Transporte } & I & 374 & 261,14 & 97665,5 & & \\
\hline & 2 & 161 & 283,94 & $457 \mid 4,5$ & & \\
\hline & Total & 535 & & & 27540,500 & 0,082 \\
\hline \multirow{3}{*}{ Segurança } & I & 436 & 300,05 & 130822 & & \\
\hline & 2 & 173 & 317,47 & 54923 & & \\
\hline & Total & 609 & & & 35556,000 & 0,256 \\
\hline \multirow{3}{*}{ Saneamento } & I & 420 & 293,36 & 123212,5 & & \\
\hline & 2 & 168 & 297,34 & 49953,5 & & \\
\hline & Total & 588 & & & 34802,500 & 0,778 \\
\hline \multirow{3}{*}{ Habitação } & I & 425 & 296,03 & 125812,5 & & \\
\hline & 2 & 167 & 297,7 & 49715,5 & & \\
\hline & Total & 592 & & & 35287,500 & 0,906 \\
\hline
\end{tabular}

Fonte: Projeto de Pesquisa Capital Social e Políticas Públicas/CPP FEEVALE. $N=613$

Como podemos notar, em todas as áreas, na medida em que se passa do nível 1 para o 2 (agora agrupado com o 3), temos sempre um aumento no escore sem exceção, na saúde 290,69 para 305,62 , na educaçáo 256,99 para 283,8 e assim sucessivamente. Aplicando-se o teste de Mann-Whitney encontramos significância na educaçáo $(\mathrm{p}=0,043)$, no esporte, lazer e cultura $(\mathrm{p}=0,030)$ e muito próximo da significância no transporte $(\mathrm{p}=0,082)$ em Novo Hamburgo.

No caso de São Leopoldo, o fenômeno parece se repetir quando aplicamos o teste Mann-Whitney diretamente ${ }^{11}$. Observando-se o Quadro 3, a variável saúde, quando aumentam os indicadores de capital social de 1 (baixo)

II Não foi possível a aplicação do teste Kruskal-Wallis devido ao fato de que havia apenas I (um) caso considerado no caso alto. 
para 2 (médio), também aumentam os escores de satisfação, de 290,23 no nível 1, para 336,57 no nível 2 e assim sucessivamente em todas as áreas.

Quadro 3 - Teste Mann-Whitney para comparação da satisfação dos serviços públicos entre os níveis agrupados do indicador de capital social (São Leopoldo)

\begin{tabular}{|c|c|c|c|c|c|c|}
\hline & INDMODIF & $\mathbf{N}$ & $\begin{array}{l}\text { Mean } \\
\text { Rank }\end{array}$ & $\begin{array}{l}\text { Sum of } \\
\text { Ranks }\end{array}$ & $\begin{array}{c}\text { Mann- } \\
\text { Whitney U }\end{array}$ & P-VALUE \\
\hline \multirow{3}{*}{ Saúde } & 1 & 467 & 290,23 & 135536,50 & \multirow{3}{*}{26258,500} & \multirow{3}{*}{0,004} \\
\hline & 2 & 133 & 336,57 & 44763,50 & & \\
\hline & Total & 600 & & & & \\
\hline \multirow{3}{*}{ Educação } & 1 & 467 & 291,38 & 136073,50 & \multirow{3}{*}{26795,500} & \multirow{3}{*}{0,012} \\
\hline & 2 & 133 & 332,53 & 44226,50 & & \\
\hline & Total & 600 & & & & \\
\hline \multirow{3}{*}{ EspLazCult } & 1 & 358 & 230,09 & 82371,50 & \multirow{3}{*}{18110,500} & \multirow{3}{*}{0,057} \\
\hline & 2 & 114 & 256,64 & 29256,50 & & \\
\hline & Total & 472 & & & & \\
\hline \multirow{3}{*}{ Transporte } & 1 & 467 & 297,31 & 138845,00 & \multirow{3}{*}{29567,000} & \multirow{3}{*}{0,337} \\
\hline & 2 & 133 & 311,69 & 41455,00 & & \\
\hline & Total & 600 & & & & \\
\hline \multirow{3}{*}{ Segurança } & 1 & 467 & 291,42 & 136091,50 & \multirow{3}{*}{26813,500} & \multirow{3}{*}{0,013} \\
\hline & 2 & 133 & 332,39 & 44208,50 & & \\
\hline & Total & 600 & & & & \\
\hline \multirow{3}{*}{ Saneamento } & 1 & 456 & 291,47 & 132910,00 & \multirow{3}{*}{28714,000} & \multirow{3}{*}{0,546} \\
\hline & 2 & 130 & 300,62 & 39081,00 & & \\
\hline & Total & 586 & & & & \\
\hline \multirow{3}{*}{ Habitação } & 1 & 423 & 269,27 & 113901,00 & \multirow{3}{*}{23997,000} & \multirow{3}{*}{0,928} \\
\hline & 2 & 114 & 268,00 & 30552,00 & & \\
\hline & Total & 537 & 290,23 & 135536,50 & & \\
\hline
\end{tabular}

Fonte: Projeto de Pesquisa Capital Social e Políticas

Públicas/CPP FEEVALE. $N=600$. Ano: 2013 
Aplicando-se o teste de Mann-Whitney, encontramos significância na saúde $(\mathrm{p}=0,004)$, na educaçáo $(\mathrm{p}=0,012)$, na segurança $(\mathrm{p}=0,013)$ e muito próximo da significância esporte, lazer e cultura $(\mathrm{p}=0,057)$.

\section{Considerações finais}

Em ambos os municípios brasileiros analisados, observamos que a variável institucional como as dotaçôes orçamentárias constituíram-se em importantes fatores explicativos da satisfaçáo destas populaçóes locais com suas políticas. Novo Hamburgo investiu mais em suas diferentes áreas do que sua cidade vizinha de Sáo Leopoldo, portanto, como demonstramos, obteve percentuais mais satisfatórios dos seus habitantes com relação às suas políticas públicas municipais. Das cinco áreas avaliadas em Novo Hamburgo em comparaçáo com São Leopoldo, quatro delas (educaçáo; saúde; segurança; esporte, lazer e cultura) superaram Sáo Leopoldo, cidade esta que apenas superou Novo Hamburgo na área de obras. Contudo, instituiçóes políticas que encontram uma sociedade organizada, horizontalizada e detentora de capital social, portanto fértil socialmente (sinergismo entre as duas variáveis), possuem melhores condiçóes de obter êxito em seus propósitos. Neste sentido, procuramos dimensionar a dotação de capital social nas duas cidades demonstrando o impacto deste sobre a satisfaçáo com as políticas municipais nestas duas cidades da regiáo do Vale do Rio dos Sinos. De fato, na medida em que melhoram os índices de capital social em uma determinada cidade, também melhoram a avaliação de desempenho das instituiçôes prestadoras de serviços daquela comunidade, isto porque os serviços sáo melhores acessados, demandados, aproveitados por uma sociedade mais organizada e horizontalizada. Demonstramos que quando as pessoas confiam mais umas nas outras a satisfação com os serviços públicos tende a aumentar tanto em Novo Hamburgo quanto em Sáo Leopoldo. No caso da cidade de Novo Hamburgo, identificamos uma ligeira melhora nos índices de capital social na comparação com São Leopoldo. Assim também identificamos que em Novo Hamburgo a satisfaçáo com as políticas públicas apresenta índices ligeiramente melhores também do que Sâo Leopoldo. Evidenciamos, desta forma, importância do capital social para a melhora da performance das políticas públicas municipais.

Evidentemente que há outras variáveis externas, para além do capital social e dotaçóes orcamentárias, que incidem sobre as políticas locais que não 
foram arroladas aqui, devido ao recorte teórico e metodológico deste artigo. Entretanto, pensamos que políticas públicas que incentivem a criaçáo de capital social em ambas as cidades, quer seja através da criaçáo de espaços de lazer ou formas alternativas de participação comunitária, em que haja a promoção em alguns casos, da "reocupaçáo do espaço público", da composiçáo do tecido social, podem sinergeticamente aliadas às instituiçóes promover uma melhora da vida dos cidadáos nestas regióes metropolitanas.

\section{Referências}

ANUÁRIO da indústria e comércio Novo Hamburgo: os patriarcas. Novo Hamburgo: Kadosch, Ediçáo 2001/2002.

BANDEIRA, P. S. Algumas hipóteses sobre as causas das diferenças regionais quanto ao capital social no Rio Grande do Sul. In: CORREA, S. M. de S. Capital social e desenvolvimento regional. Santa Cruz do Sul: Edunisc, 2003. p. 15-59.

BAQUERO, M. Democracia e desigualdades na América Latina: novas perspectivas. Porto Alegre: Editora da UFRGS, 2007.

Qual democracia para América Latina? Capital social e empoderamento são a resposta? Porto Alegre: Editora da UFRGS, 2013.

BASTOS, F. A.; SANTOS, E.; TOVO, M. F. Capital social e sistema único de saúde (SUS) no Brasil. Saúde e Sociedade, v. 18, n. 2, p. 177-188, 2009.

BOSCHI, R. R. Descentralizaçáo, clientelismo e capital social na governança urbana: comparando Belo Horizonte e Salvador. Dados: Revista de Ciências Sociais, Rio de Janeiro, v. 42, n. 4, 1999, p. 655-690.

FERNANDES, A. A. O capital social e a análise institucional e de políticas públicas. Revista de Administração Pública, Rio de Janeiro, v. 36, n. 3, p. 375-398, 2002.

FUKUYAMA, F. Confiança: as virtudes sociais e a criação da prosperidade. Rio de Janeiro: Rocco, 1996.

The primacy of culture. In: LARRY, D.; PLATTNER, M. F. (Org.). The Global Resurgence of Democracy. Second Edition. Baltimore and London: The Johns Hopkins University Press, 1996.

HALL, P. A.; TAYLOR, R. C. R. As três versóes do neo-institucionalismo. Lua Nova, n.58, p. 193-224, 2003.

MONASTERIO, L. M. Medindo o capital social: uma análise das regióes do Rio Grande do Sul. In: CORREA, S. M. de S. Capital social e desenvolvimento regional. Santa Cruz do Sul: Ed. Edunisc, 2003. p. 61-84. 
NORTH, D. C. Instituciones, cambio institucional y desempeńo económico. México: Fondo de Cultura Económica, 2001.

NUNES, M. F. O negro no mundo alemáo: cidade, memória e açóes afirmativas no tempo da globalizaçáo. 2009. 255 f. Tese (Doutorado em Antropologia Social)-Universidade Federal de Santa Catarina, Florianópolis, 2009.

PASE, H. L.; SANTOS, E. R. Capital social e políticas públicas na América Latina. In: BAQUERO, M. (Org.). Cultura(s) política(s) e democracia no século XXI na América Latina. Porto Alegre: UFRGS, 2011. v. 1, p. 69-93.

PRZEWORSKI, A. As instituiçóes são a causa primordial do desenvolvimento econômico? Novos Estudos Cebrap, n. 72, p. 59-77, jul. 2005.

PUTNAM, R. Comunidade e democracia: a experiência da Itália Moderna. Rio de Janeiro: Ed. FGV, 2000.

. Bowling alone: America’s declining social capital. In: LARRY, D.; PLATTNER, M. F. (Org.). The Global Resurgence of Democracy. Second Edition. Baltimore and London: The Johns Hopkins University Press, 1996.

SANTOS, E. R., et al. Contrastes regionais que fazem diferença no Rio Grande do Sul: capital social e desempenho institucional. Revista Brasileira de Gestáo e Desenvolvimento Regional, v. 6, n. 2, p. 157-187, maio-ago. 2010.

SIEDENBERG, D. R. Condicionantes político-administrativos do desenvolvimento regional no Rio Grande do Sul: a experiência dos COREDES. In: WITTMANN, M. L.; RAMOS, M. P. Desenvolvimento regional: capital social, redes e planejamento. Santa Cruz do Sul: Ed. Edunisc, 2004. p. 135-158.

SOUZA, C. Políticas públicas: uma revisão de literatura. Sociologias, Porto Alegre, ano 8, n. 16, p. 20-45, jun. 2006.

TRIBUNAL DE CONTAS DO ESTADO. Disponível em: <http://wwwl.tce.rs.gov.br/ aplicprod/f?p=20001:74:2916824971285883>.

WEBER, M. Economia e sociedade. Brasília, DF: UnB, 1999. v. 2.

WEBER, R. Mosaico identitário: história, identidade e turismo nos municípios da Rota Romântica-RS. 2006. 310 f. Tese (Doutorado em História)-Universidade Federal do Rio Grande do Sul, Porto Alegre, 2006. 


\section{Social capital and public policy in Brazil: Comparing two cities in the metropolitan region of Porto Alegre}

\section{Abstract}

The objective of this paper is to analyze the reasons that determine the satisfactory evaluation of Public Policies, especially on Rio Grande do Sul in two cities in the metropolitan region of Porto Alegre: Novo Hamburgo and São Leopoldo. Therefore, after reviewing the relevant literature, we build a theoretical framework that takes into account synergistic both formal institutional implications itself (new institutionalism) as well as the value patterns local (political culture). Our working hypothesis is that social capital, own the local political culture existing in cities screen consists of an allied political institutions, because it favors positive evaluation of the performance of local Public Policies. The methodology uses the results of two quantitative surveys, household surveys type applied in Novo Hamburgo and São Leopoldo, with probability samples totaling about 1.200 questionnaires, with a sampling error of $4 \%$ and $95 \%$ confidence, between the months of January and April 2012 and June and July 2013 by the Center of Research and Planning at the Feevale University (CPP / Feevale), as well as documentary research the sites of these municipalities, IBGE, TCE (Court of the State of Rio Grande do Sul) and FEE (Foundation Economics and Statistics of Rio Grande do Sul).

Keywords: Social capital. Institutions. Political culture. 